\title{
ERCP-Related Duodenal Perforation; The Prevention and Management
}

\author{
Hong Ja Kim', Seon Mee Park ${ }^{2}$ \\ ${ }^{1}$ Department of Internal Medicine, Dankook University College of Medicine, Cheonan, ${ }^{2}$ Department of Internal Medicine, Chungbuk National \\ University College of Medicine, Cheongju, Korea
}

Endoscopic retrograde cholangiopancreatography (ERCP) is an invasive procedure carrying potential complication such as pancreatitis, hemorrhage, perforation and cholangitis. Most of those complications are mild and usually need a short additional hospitalization periods. Perforation, however, often requires surgical intervention and in this case, the rate of mortality is up to $10 \%$. Prompt diagnosis and proper management are key determinants for successful outcome. For this, endoscopist should be aware of possibility of perforation before procedure especially in high risk patients with altered anatomy such as prior Billroth II or Roux-en-Y anastomosis. After diagnosis of perforation, multidisciplinary approach involving medical, surgical and radiologic interventional subspecialties, is essential. Usually, surgical treatment is needed for type I free wall perforation and medical and endoscopic treatments are recommended for type II-IV perforation. Recently, several anecdotal studies reported successful endoscopic treatment using new devices for type I duodenal wall perforation but it is not warranted that endoscopic treatments can substitute the surgical intervention.

Korean J Pancreatobiliary 2016;21(2):61-67

Keywords: Cholangiopancreatography, Endoscopic retrograde, Perforation

\begin{abstract}
Received Mar. 4, 2016
Revised Apr. 4,2016

Accepted Apr. 12, 2016
\end{abstract}

Corresponding author: Hong Ja Kim

Department of Internal Medicine, Dankook University College of Medicine, 201 Manghyangro, Dongnam-gu, Cheonan 31116, Korea

Tel. +82-41-550-3917 Fax. +82-41-550-3918

E-mail; hjkimjung@hotmail.com

This is an Open Access article distributed under the terms of the Creative Commons Attribution Non-Commercial License (http:/ creativecommons.org/licenses/by-nc/3.0/) which permits unrestricted non-commercial use, distribution, and reproduction in any medium, provided the original work is properly cited.

Copyright $@ 2016$ by The Korean Journal of Pancreas and Biliary Tract

\section{서 론}

Endoscopic retrograde cholangiopancreatography (ERCP)와 연관된 합병증의 대부분은 사망률 $1 \%$ 미만으로 임상증상이 경미하고 짧은 입원기간을 요하는 반면, $\mathrm{ERCP}$ 후 발생한 천공은 사망률이 $10 \%$ 까지 보고되는 ERCP 후 합 병증 중 가장 두려운 합병증이다. ${ }^{1-3}$ 천공 발생 직후 즉각적으 로 인식하고, 이에 따라 조기에 항생제 치료를 동반한 보존 적 치료, 중재적 시술, 수술 등의 여러 가지 다양한 치료 중 시술 환자의 임상 및 천공 상황에 맞는 적절한 치료를 시행
하는 것이 성공적인 치료 성적을 결정짓는 중요한 요소로 알 려져 있다. ${ }^{4,5}$ 그러나 천공은 발생 증례가 드물어 적절한 치료 에 대한 가이드라인이나 합의가 체계적으로 확립되어 있지 않아 의료진이 경험적으로 판단하여 치료를 선택하고 있다. 본 고찰은 $\mathrm{ERCP}$ 후 발생한 천공의 문헌고찰을 통해 천공의 예방법과 함께 체계적인 치료법에 대해 제시하고자 하였다. 


\section{본 론}

\section{1. 분류}

$\mathrm{ERCP}$ 후 발생한 천공을 Howard 등 ${ }^{6}$ 은 간편하게 1 군; 유 도철선 천공(guide wire perforation), 2 군; 유두부 주위 천공 (periampullary perforation), 3 군; 십이지장 천공(duodenal perforation)으로 분류하였으며 그 외에도 다양한 분류법이 있다(Table 1). ${ }^{7}$ 최근에는 발생기전, 해부학적 위치, 중증도 등을 종합적으로 고려하여, 치료 방침의 결정에 유용한 Stapfer에 의해 제안된 분류가 흔히 사용된다. ${ }^{8}$ Stapfer의 분 류는 중증도의 순서에 따라 천공을 1형-4형으로 나누며 1형 은 십이지장 외벽 또는 내벽의 천공(lateral or medial wall), 2 형은 유두부주위 천공(perivaterian injury), 3형은 원위부 담 도 손상(distal bile duct), 4형은 후복강 공기만 관찰되는 경 우이다. 4형은 진정한 천공으로 취급되지 않으며 주로는 십 이지장의 개통을 위해 송기된 과도한 공기와 관련이 있으며 이들 공기가 십이지장 벽 내로 일부 이동한 것으로 추정되며 실제 증상은 거의 유발하지 않는다. 무증상의 환자에서도 ERCP 후 13-29\%까지 후복강 내에 공기가 관찰되었다는 보 고들이 있다. ${ }^{9-10}$ 천공의 분류 방법, 발표 시기에 따라 논문마 다 다소 차이는 있으나 1 형 천공은 내시경 자체에 의해 십이 지장의 외측 벽에 손상이 발생한 경우로 $15-20 \%$ 를 차지하 며, 이전에 시행한 수술로 장관의 해부학적 변형이 있는 경 우에 흔히 발생한다. 변형된 비정상적인 주행 방향은 측시경 의 원만한 주행을 방해하며 수술 후 협착, 변형된 고정점등 은 내시경 삽입시 과도한 신전이나 굴곡을 유발하고 이는 결 국 내시경자체로 인한 외상성 십이지장손상의 가능성을 증 가시킨다. 2형 및 3형 천공은 70-80\%를 차지하며 유두 팽대 부 주위에 주로 발생한다. 이 중 2 형 천공은 유두부 절개도 (sphincterotomy)나 유도 철선(guidewire)에 의해 대부분 발
생한다. 어려운 삽관 등 유두부 주위에서 오랫동안 처치를 하는 경우, 유두부 주위 게실과 같은 해부학적 이상이 있는 경우, 오디괄약근 기능 이상, 유두부 풍선 확장술 시행 (endoscopic papillary balloon dilatation, EPBD), 예비 절개 술 시행, zipper cut 시행 등이 위험인자로 관련이 있다는 보 고가 있다. 3 형 천공의 경우 유도철선이나 바스켓 등의 기계 적 조작 중 담도 손상이 발생한 경우에 해당하는데, 흔히 경 험하는 예로서 담도 협착부위의 확장 중 담도가 손상되는 경 우, 담석이 바스켓에 감돈되거나 거대 담석이 담도에 감돈되 어 이를 제거하기 위해 과도한 물리적 손상이 반복적으로 담 도에 가해져서 발생하는 경우 등이 있다.

\section{2. 발생률 및 예후}

2009년 Avgerinos ${ }^{11}$ 이 9년 동안 $\mathrm{ERCP}$ 를 시행받은 환자 4,358 명을 조사한 보고에 따르면 천공은 15 명 $(0.34 \%)$ 에서 발생하였고 평균 입원기간은 21일이었다. 수술적 치료가 필 요한 경우는 더 긴 입원이 필요하였는데 이 경우 천공의 진 단부터 수술까지 소요된 시간이 중요한 예후인자였다. 실제 수술이 지연된 환자의 평균 사망률은 $20 \%$ 로 필요하다고 판 단된 경우 빠른 수술이 좋은 예후와 관련있음을 시사한다. 2012년 Machado ${ }^{12}$ 가 10년간 ERCP 후 천공으로 보고된 문헌 들을 취합하여 총 251 예의 천공을 분석한 자료에 따르면 천 공의 원인으로 유두부 절개도에 의한 경우가 $25.9 \%$, 유도철 선에 의한 경우가 $21.5 \%$, 내시경 자체에 의한 경우는 $14.3 \%$, 스텐트에 의한 경우가 $8 \%$ 였고 원인미상의 경우도 $8 \%$ 를 차 지하였다. $34.5 \%$ 에서 십이지장벽에 천공이 발생하였고 유 두부주위에 $31.3 \%$, 담도에 $23 \%$ 발생하였다. 보존적 치료가 156 예 $62 \%$ 에서 시행되었고 이들의 $92 \%$ 가 성공하였으며 실 패한 11 명 중 10 명에서 수술을 시행하였다. 사망률은 $6 \%$ 로 다른 보고보다 낮았으며 사망한 환자의 $25 \%$ 가 발생 후 3 일

Table 1. Various classifications of ERCP-related duodenal perforation

\begin{tabular}{|c|c|c|c|c|c|}
\hline \multicolumn{2}{|c|}{ Stapfer, et al. ${ }^{8}$} & \multicolumn{2}{|r|}{ Howard, et al. ${ }^{6}$} & \multicolumn{2}{|r|}{ Enns, et al. ${ }^{7}$} \\
\hline Type & Definition & Type & Definition & Type & Definition \\
\hline I & Lateral duodenal Wall injury & 1 & Duodenal injury remote from papilla & Duodenal & $\begin{array}{l}\text { Not related to sphincterotomy } \\
\text { guidewire (scope related) }\end{array}$ \\
\hline$\|$ & Perivaterian injury & $\|$ & $\begin{array}{l}\text { Periampullary injury (duodenal wall } \\
\text { and ducts) }\end{array}$ & Sphincterotomy-related & Periampullary \\
\hline III & Ductal injury (wire/basket) & III & Guidewire perforations (of ducts) & Guidewire-related & Ductal or periampullary injury \\
\hline V & Retroperitioneal air alone & IV & NA & Others & Dilatations (bile duct injury) \\
\hline
\end{tabular}

ERCP, endoscopic retrograde cholangiopancreatography; NA, not applicable. 
이 지난 후에 천공이 지연되어 진단되고 치료가 시작된 경우 로 천공의 즉각적인 인식 및 조기 대응이 중요함을 다시 증 명하였다.

\section{3. 위험인자}

천공 발생의 위험인자에 관한 후향적 연구에서 보고된 환 자 관련 인자로 오디괄약근 기능이상, 여성, 고령자, 정상 빌 리루빈, 이전의 수술 기왕력, Billroth II 위절제술 등의 비정 상 해부학적 구조 등이 있으며 기술 관련 인자로는 어려운 삽관, 유두부 풍선확장술 시행 등이 관련이 있다. 그러나 최 근의 전향적, 다기관 연구에 의하면 악성종양과 예비절개술 2 가지의 경우만이 위험인자에 해당된다는 상이한 보고도 있 어 위험인자에 대해서는 향후 대규모의 조사가 필요하겠 다. ${ }^{4,7,13,14}$

\section{4. 증상 및 진단}

$\mathrm{ERCP}$ 시 발생하는 십이지장 천공은 특히 측시경을 이용 한 검사이므로 내시경 검사 중 주의 깊게 관찰하지 않으면 발견이 어렵다. 또한 ERCP는 흔히 깊은 수면상태에서 시행 되므로 천공에 의한 통증에 대한 환자의 반응이 감소되어 있 어 조기 발견을 더욱 어렵게 한다. ${ }^{8} .15$ 그러나 조기 진단 및 이 에 따른 즉각적인 치료가 예후의 결정적 인자이므로 시술자 는 조기 진단을 위해서 각별히 노력하여야 한다. 이를 위해 서는 무엇보다 천공의 가능성에 대한 시술자의 경각심이 필 요하다. 시술자는 천공의 위험인자에 대해 미리 숙지하여 십 이지장 유두부 주위에 게실이 있는 경우나 수술 기왕력으로 인한 변형이 있는 경우, 또는 시술이 까다로웠던 경우 등에 는 내시경 시술 중이나 후에 주의 깊은 관찰이 필요하다. 또 한 검사 후 심한 복통이나 반발통을 호소하거나 피부하기종, 호흡 곤란 등의 천공 의심 증상을 면밀히 관찰하여야 한다. 그러나 천공과 함께 ERCP 후 췌장염이 발생하였을 때는 증 상만으로 천공 발생을 판단하기 어려우며 영상검사가 감별 진단에 도움이 된다.

$\mathrm{ERCP}$ 시행 중 갑자기 복강내 지방조직이 보이거나 타 장 기가 보이는 경우, ERCP 시 조영제의 복강내 유출을 보이는 경우 천공을 쉽게 감지할 수 있으나 크기가 작고 관찰이 어 려운 위치에 발생한 경우는 검사 중 진단이 어려울 수 있다. 이 경우 ERCP 중 의심부위에 조영제를 투여해보거나 gatrografin을 이용한 위장관 조영술로 조영제의 내강 외 유출을 확인할 수 있으나 실제 조영제의 유출이 관찰되는 경우는 십
이지장 외벽의 천공이나 유두부주위 천공 중에서도 큰 크기 의 천공이 발생한 경우에 해당하며 미세한 천공은 위의 방법 으로 발견이 어렵다. 단순 촬영으로도 신장주위의 후복강 가 스나 복강내 유리가스 여부를 확인할 수 있으나 단순촬영검 사에서 불명확하며 환자가 복통을 호소하는 경우 경구 조영 제를 추가한 비조영증강 전산화 단층촬영 검사는 큰 위험 없 이 쉽게 복강 및 후복강내 유리가스 및 천공부위를 발견할 수 있어 미세 천공 진단에 추천된다. 복강내 천공이 확인된 경우 필요에 따라 조영제를 사용한 $\mathrm{CT}$ 를 추가적으로 검사하 면 천공주위 액체의 저류나 주변부 염증상태까지도 확인 할 수 있어 천공 및 이와 동반된 복막염 진단의 가장 민감한 검 사이다. 그러나 검사 중 과도하게 송기된 공기로 인해 실제 천공의 크기와 복강내 공기의 양이 직접적으로 비례하지는 않을 수 있으므로 영상소견은 임상증상과 함께 신중하게 판 단해야 한다..$^{15-17}$ 천공이 확인된 경우 즉시 항생제를 사용하 고 정맥내 수액 주입을 시행하여야 한다. 천공이 있는 환자 에서 12 시간 정도가 경과하면 복강내로 유출된 삼출액의 여 부에 따라, 고열, 호흡곤란, 빈맥, 백혈구 증가증을 보이며 이 경우 복막염의 발생을 의심하여야 한다.

\section{5. 치료}

일단 천공이 확진되면 당황하지 않고 천공의 정도에 맞는 적절한 치료법을 선택하여야 한다. 특히 Baron 등 $^{16}$ 이 발표 한 “내시경시술 후 천공 발생시 유의할 십계명”과 같은 권고

Table 2. Ten considerations for the endoscopic peroration adapted from Baron $\mathrm{TH}$, et al. ${ }^{16}$

1. Prompt recognition of endoscopic perforation is essential to improvement in outcome.

2. The presence of extraluminal air does not automatically mean the need for surgery

3. The volume of extraluminal air is not necessarily proportional to the size of the perforation.

4. Extraluminal air per se is not infectious.

5. Extraluminal air under pressure is a medical emergency.

6. Extraluminal air can dissect into distant spaces.

7. Residual extraluminal air may persist without clinical significance.

8. Perforations tend to close after drainage or diversion of luminal contents.

9. Oral, rectal, or injected contrast material extravasation should elicit prompt intervention.

10. Failed endoscopic closure of a perforation generally requires surgical intervention. 


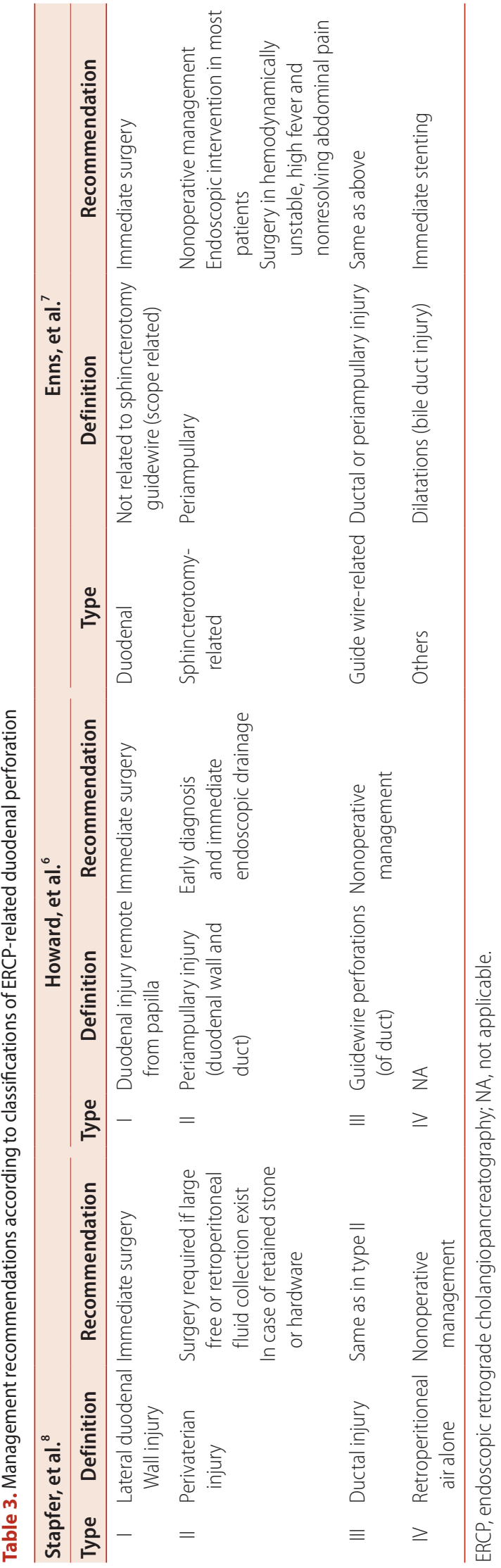

안은 치료내시경 시술이 보편화되어 시술 후 천공을 경험할 가능성이 증가하는 현 시점에서 시술자가 환자의 천공 상태 을 파악하여 적절한 치료법을 선택하는데 도움을 줄 수 있다 (Table 2). 천공의 치료를 위해 천공의 위치, 임상 상황, 영상 학적 소견 등 여러 인자들을 종합적으로 고려하여야 한다. 신속한 진단과 적절한 치료는 이환율과 사망률을 줄일 수 있 으며 치료 결정 과정에서 외과 의사와의 적절한 연계가 필요 하다. ${ }^{18.19}$ Table 3 에서와 같이 천공의 분류에 따라 권고 치료 법이 다소 차이를 보이나 전통적으로는 제 1 형 십이지장 천 공은 수술적 치료가 일차 치료이다. 2형 및 3형 천공의 경우 주로 유도철선이나 괄약근절개도에 의한 후복강내 천공으 로 이는 주로 내시경 자체에 의해 발생하는 1형 천공에 비해 크기가 적고 복강내로 흘러 나간 체액량도 상대적으로 적어 환자의 상태가 안정적이고 내시경적 보조 치료가 가능한 경 우 비수술적 치료가 권고되고 있다. 실제 유두부주위 천공 발생시 신속한 진단 후 광범위 항생제 투여와 함께 비위배액 관과 경비담도배액관을 통한 담즙 및 십이지장액을 배액하 고 규칙적인 재검사를 시행하였을 때 50-90\%에서 성공적으 로 치료되며 환자의 $86 \%$ 에서 수술의 필요성을 줄일 수 있었 다고 보고하고 있다. ${ }^{18.19}$ 최근에는 담도내에 완전 피막형 자 가확장 금속 스텐트(full-covered self expandable metal stent, FCSEMS)를 삽입하여 천공부위를 통한 복강내 액체의 유출 을 차단하여 성공적으로 치료한 보고도 늘고 있다. ${ }^{20.21}$ 실제 Assalia 등 ${ }^{17}$ 의 복막 자극 증상, 증상의 악화, 쇼크 발생과 같 은 임상적 기준에 따른 치료의 선택과 예후와의 관계에 대한 조사에서 임상적 기준에 따른 경우 $90 \%$ 가 내과적으로 치료 하였다. 수술이 필요한 경우는 $10 \%$ 로 내시경에 자체에 의한 장천공 2예와 함께 유두부 주위 천공이지만 액체유출량이 많은 1 예였다. 임상적 기준에 따른 치료의 선택은 천공의 크 기나 천공 발생 기전에 따른 천공의 중증도와도 잘 연관되나 일부 환자에서는 2형 및 3형 천공임에도 불구하고 즉각적인 수술이 필요하였으며, 심각한 동반질환이 있는 경우 비수술 적 치료 중 사망한 예도 있어 2형 및 3형의 경우라도 무조건 적으로 비수술적 치료를 우선으로 하기보다 환자의 임상적 상황에 맞는 적절한 선택을 하는 것이 중요하다고 주장하였 다. 실제 보존적 치료가 실패하여 수술적 치료를 시행하는 경우 지연된 시간이 수술적 치료의 예후를 결정하는 중요인 자이므로 비수술적 치료와 조기 수술적 치료가 필요한 환자 의 적절한 선별은 여전히 어려운 문제이다. ${ }^{12.14}$ Figure 1은 현 재까지 추천되는 $\mathrm{ERCP}$ 연관 십이지장 천공 치료의 가이드 


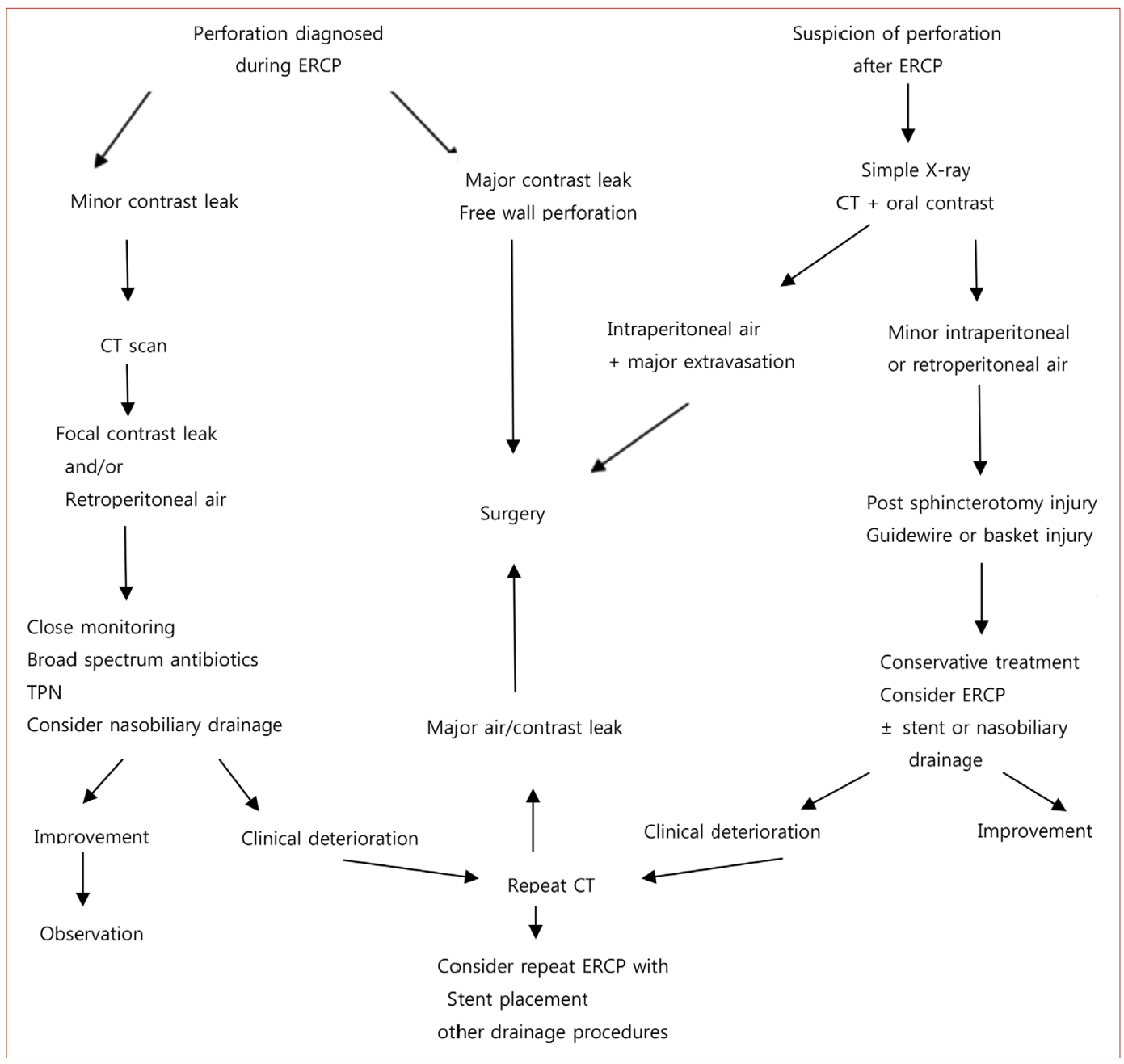

Figure 1. Treatment algorithm for ERCP-related duodenal perforation. ERCP, endoscopic retrograde cholangiopancreatography; TPN, total parenteral nutrition; CT, computed tomography.

라인을 정리하였다.

1 형 천공의 경우 대부분 즉각적인 수술이 필요하다는 데는 이견이 없었다. 그러나 최근 내시경적 점막하 박리술의 광범 위한 시행에 따라 천공부위의 내시경적 결찰 기술 및 기구의 눈부신 개발에 따라 조기수술이 필요하다고 알려져 있던 1 형 천공에서도 이들 기구를 이용한 밴드결찰술, endoclip을 이용한 clipping, endoclip과 endoloop의 사용, fibrin glue와 endoclip을 이용한 치료 사례가 보고되고 있다. 또한 최소 침 습적 수술의 일환으로 자연 개구부에 인공적 누공을 만들어 복강내에서 수술을 시행하는 natural orifice transluminal endoscopic surgery (NOTES)의 기구가 ERCP 후 천공의 치 료에도 활용되어 through the scope (TTS) clipping, over the scope (OTS) clipping 등의 신기술을 응용하여 큰 크기의 1 형 천공도 비수술적으로 치료하였다는 보고도 있으나 ${ }^{22-30}$ 증
례보고 수준이므로 조심스러운 접근이 필요하다. 이러한 신 기술은 천공의 크기, 위치 등을 종합적으로 고려한 적절한 환자의 선별이 중요하며 내시경적 숙련이 필요하므로 보편 적인 치료방침으로 확립되기 위해서는 더 많은 경험의 축적 이 필요할 것으로 생각된다.

\section{6. 예방}

임상적으로 문제가 되는 1형 천공은 대부분이 Billroth II 수술이나 Roux-en-Y 문합수술 등으로 변형된 해부학 구조 를 가지고 있는 경우에 높은 빈도로 발생한다. 이러한 환자 에서 $\mathrm{ERCP}$ 시술시 천공의 예방을 위해서 측시 내시경보다 전방내시경을 선택하거나, 캡을 장착한 전방 내시경 사용, overtube를 이용하는 방법, 풍선 도움하 소장내시경 등 다양 한 방법이 소개되고 있다. ${ }^{31-33}$ 특히 전방내시경의 경우 십이 
지장 삽입률, 담관 삽입 성공률은 측시경과 유사하며 천공등 의 합병증 발생의 측면에서 측시경보다 안전하다는 보고들 이 많아 적극적인 사용이 권장된다. ${ }^{32,33}$ 유두부주위에 큰 게 실이 있거나 이전 수술로 유두부의 위치가 비정상적인 환자 에서 괄약근 절개가 필요한 경우 통상적인 유두괄약근 절개 도를 이용한 절개보다 풍선 확장술을 이용한 괄약근 성형술 이 2형이나 3형 천공의 예방에 도움이 될 수 있다.

\section{결 론}

ERCP 후 천공의 발생률은 $0.1 \%$ 에서 $0.6 \%$ 로 비교적 낮은 발생율을 보이나 사망률이 $10 \%$ 까지 보고되는 ERCP 후 합 병증 중 가장 두려운 합병증이다. 조기 진단 및 이에 따른 즉 각적인 치료가 예후의 결정적 인자로서 시술자는 천공의 가 능성에 대해 항상 경각심을 가지고 시술을 시행하여야 한다. 특히 Billroth II 수술이나 Roux-en-Y 문합수술 등 수술 기왕 력이 있거나 시술이 어려웠던 경우 천공발생의 가능성을 염 두에 두고 시술 중 뿐 아니라 시술 후에도 환자의 증상 및 영 상소견을 면밀히 관찰하여 조기 진단을 위해서 노력하여야 한다. 천공의 치료로 천공의 위치, 임상상황, 영상학적 검사 등 여러 인자들을 종합적으로 고려해야 선택하는데 현재까 지는 내시경 자체에 의한 1 형 장천공의 경우 즉각적인 수술 이 권고된다. 2형 및 3형 장 천공의 경우 내과적 치료가 우선 적으로 고려되나 외과 의사와의 연계를 통하여 환자의 임상 증상을 종합적으로 판단하여 적절하게 선택하여야 한다. 최 근 신기술의 개발로 1 형 천공에 대해서도 내시경적 기구를 이용하여 성공적으로 치료한 보고가 늘고 있지만 아직 수술 적 치료를 대체하기는 어렵다. 이상의 지침에 따른 신속한 진단과 적절한 치료는 이환율과 사망률을 줄일 수 있을 것으 로 기대된다.

\section{요 약}

$\mathrm{ERCP}$ 와 연관된 합병증의 대부분은 사망률 $1 \%$ 미만으로 임상증상이 경미하고 짧은 입원기간을 요하는 반면 ERCP 후 발생한 천공은 사망율이 $10 \%$ 까지 보고되는 ERCP 후 합 병증 중 가장 두려운 합병증이다. 천공 발생 직후 즉각적으 로 인식하고, 이에 따라 조기에 시술 환자의 임상 및 천공 상 황에 맞는 적절한 치료를 시행하는 것이 성공적인 치료 성적 을 결정짓는 중요한 요소로 알려져 있다. 이를 위해 시술자
는 Billroth II 수술이나 Roux-en-Y 문합수술 등으로 변형된 해부학 구조를 가지고 있는 경우나 시술이 어려웠던 경우 천 공발생의 가능성을 염두에 두고 환자의 증상 및 영상소견을 면밀히 관찰하여 조기진단을 위해서 노력하여야 한다. 천공 의 치료로 현재까지는 내시경 자체에 의한 1 형 장천공의 경 우 즉각적인 수술이, 2형 및 3형 장 천공의 경우 내과적 치료 가 우선적으로 고려되나 최근 신기술의 개발로 점차 1형 천 공에 대해서도 내시경적 기구를 이용하여 성공적으로 치료 한 보고가 늘고 있으나 아직 수술적 치료를 대체하기는 어렵 다.

국문 색인: 내시경적 역행성 담췌관조영술, 천공, 합병증

\section{Conflicts of Interest}

The author has no conflicts to disclose.

\section{REFERENCES}

1. Freeman ML, Nelson DB, Sherman S, et al. Complications of endoscopic biliary sphincterotomy. N Engl J Med 1996;335:909-918.

2. Masci $E$, Toti $G$, Mariani A, et al. Complications of diagnostic and therapeutic ERCP: a prospective multicenter study. Am J Gastroentero 2001;96:417-423.

3. Cotton JB, Curran CC. Quality indicators, including complications, of ERCP in a community setting: a prospective study. Gastrointest Endosc 2009;70:457-467.

4. Tarun Rustagi, Priya A Jamidar. Endoscopic Retrograde Cholangiopancreatography-Related Adverse Events. Gastrointest Endoscopy Clin N Am 2015;25:97-106.

5. Lai CH, Lau WY. Management of endoscopic retrograde cholangiopancreatography-related perforation. Surgeon 2008;6:45-48.

6. Howard TJ, Tan T, Lehman GA, et al. Classification and management of perforations complicating endoscopic sphincterotomy. Surgery 1999;126:658-663.

7. Enns R,Eloubeidi MA, Mergener $K$, et al. ERCP- related perforations: risk factors and management. Endoscopy 2002;34:293-298.

8. Stapfer M, Selby RR, Stain SC, Kathouda N, Parekh D, Jabbour N, Grey D. Management of duodenal perforation after endoscopic retrograde cholangio-pancreatography and sphincterotomy. Ann Surg 2000:232;191-198.

9. Genzlinger JL, McPhee MS, Fisher JK, Jacob KM, Helzberg JH. Significance of retroperitoneal air after endoscopic retrograde cholangiopancreatography with sphincterotomy. Am J Gastroenterol 1999:94:1267-1277. 
10. De Vries JA, Duijm LE, Dekker W, Guit GL, Ferwerda J, Scholten ET. CT before and after ERCP Detection of pancreatic pseudotumor, asymptomatic retroperitoneal perforation and duodenal diverticulum. Gastrointest Endosc 1997;45:231-235.

11. Avgerinos DV, Llaguna OH, Lo AY, Voli J, Leitman IM. Management of endoscopic retrograde cholangiopancreatography: related duodenal perforations. Surg Endosc 2009;23:833-838.

12. Machado NO. Management of duodenal perforation post -endoscopic retrograde cholangiopancreatography. When and whom to operate and what factors determine the outcome? A reviw article. JOP 2012;13:18-25.

13. Loperfido S, Angelini G, Benedetti G, et al. Major early complications from diagnostic and therapeutic ERCP: a prospective multicenter study. Gastrointest Endosc 1998;48:1-10.

14. Williams EJ, Taylor S, Fairclough P, et al. Risk factors for complication following ERCP; results of a large-scale, prospective multicenter study. Endoscopy 2007;39:793-801.

15. Avgerinos DV, Liaguna OH, Lo AY, Voli J, Leitman IM. Management of endoscopic retrograde cholangipancreatography related duodenal perforations; Surg Endosc 2009;23:833-838.

16. Baron TH, Wong Kee Song LM, Zielinski MD, Emura F, Fotoohi M, Kozarek RA. A Comprehensive approach to the management of acute endoscopic perforations. Gastrointest Endosc 2012;76;838-859.

17. Assalia A, Suissa A, llivitzki $A$, et al. Validity of clinical criteria in the management of endoscopic retrograde cholangipancreatography related duodenal perforations. Arch Surg 2007;142:1059-1064.

18. Morgan KA, Fontenot BB. Ruddy JM, Mickey S, Adams DB. Endoscopic retrograde cholangiopancreatography gut perforations: when to wait! When to operate! Am Surg 2009;75;477-483.

19. Knudson K, Raeburn CD, McIntyre RC Jr, et al. Management of duodenal and pancreaticobiliary perforations associated with periampullary endoscopic procedures. Am J Surg 2008;196;975-981.

20. Vezakis A, Fragu;idis G, Natos C, Yiallporou A, Polyorou A, Voros D. Closure of a persistent sphincterotomy-related duodenal perforation be placement of a covered self-expandable metal stent. World J Gastroenterol 2011;17:4539-4541.

21. Park WY, Cho KB, Kim ES, Park KS. A case of ampullary perforation treated with temporally covered metal stent. Clin Endosc 2012:45;177-
180.

22. Lee TH, Bang BK, Jeong Jl, et al. Primary endoscopic approximation suture under cap-assisted endoscopy of an ERCP- induced duodenal perforation. World J Gastroenterol 2010;16:2305-2310.

23. Sebert DG. Use of an endoscopic clipping device to repair a duodenal perforation. Endoscopy 2003;35:189.

24. Kim KW, Lee TH, Park SH, et al. A primary repair with hemoclips and fibrin glue injection in biliary sten induced duodenal perforation. Korean J Gasttttrointest Endosc 2011;42:437-441.

25. Mutignani M, lacopini F, Dokas S, et al. Successful endoscopic closure of a lateral duodenal perforation at ERCP with fibrin glue. Gastrointest Endosc 2006;63:725-727.

26. Buffoli F, Grassia R, Iritano E, Bianchi G,Dizioli P, Staiano T. Endoscopic retroperitonel fatpexy of a large ERCP-related jejunal perforation by using a new over-the-scope clip device in Bilroth II anatomy (with video). Gastrointest Endosc 2012;75:1115-1117.

27. Shahzad Haider, Michel Kahaleh. The Use of Endoscopic Clipping Devices in the Treatment of latrogenic Duodenal Perforation. Gastroenterol Hepatol 2010;6:660-661.

28. Baron TH, Wong Kee, Song LM, Zielinski MD, Emura F, Fotoohi M, Kozarek RA. A comprehensive approach to the management of acute endoscopic perforations (with videos). Gastrointest Endosc 2012;76: 838-859.

29. Han JH, Lee TH, Jung Y, et al. Rescue endoscopic band ligation of iatrogenic gastric perforations following failed endoclip closure. World J Gastroenterol 2013;19:955-959.

30. Kwon $\mathrm{Cl}$, Song SH, Hahm KB, Ko KH. Unusual complications related to endoscopic retrograde cholangiopancreatography and its endoscopic treatment. Clin Endosc 2013;46:251-259.

31. Kruzynske FC, Romagnuolo J, Brock AS. Success of single balloon enteroscopy in patients with surgically altered anatomy. Gastrointest Endosc 2015;82:319-324.

32. Byun JW, Kim JW, Sung SY, et al. Usefulness of forward-viewing endoscopic retrograde cholangiopancreatography in patients with bilroth II gastrectomy. Clin Endosc 2012;45:397-403.

33. Park TY, Kang JS, Song TJ, et al. Outcomes of ERCP in Billroth II gastrectomy patients. Gastrointest Endosc 2015 Nov 4. [Epub ahead of print] 